\title{
A prospective study of the relationship between patient character and blood pressure in dental implant surgery
}

\author{
Masahiro Wada*, Syunta Miwa, Tomoaki Mameno, Tohru Suganami, Kazunori Ikebe and Yoshinobu Maeda
}

\begin{abstract}
Background: Patients often suffer from physical and mental stress in dental implant surgery. The aim of this prospective study is to investigate the relationship between patient character and blood pressure in dental implant surgery.

Methods: Fifteen patients were recruited for the present study. All patients had never received implant treatment in the past. To evaluate the patients' personality trait, NEO-Five Factor Inventory (NEO-FFI) was used. All patients answered 50 questions at the first visit and divided in five dimensions: neuroticism, extraversion, openness, agreeableness, and conscientiousness. The index of physical stress was evaluated by blood pressure and pulse rate.

Results: Ten females and five males (mean $55.5 \pm 10.6$ years) were evaluated in this study. A significant positive correlation was found between elevation rate of diastolic blood pressure/mean blood pressure and neuroticism score $(r s=0.584,0.526, p<0.05)$. On the other hand, there was no significant correlation between systolic blood pressure elevation and neuroticism score.

Conclusions: In this limited study, there was significant correlation between neuroticism character and diastolic blood pressure or mean blood pressure rising in patients who received implant surgery.
\end{abstract}

Keywords: Implant surgery, Personal traits, Blood pressure

\section{Background}

Implant prosthesis has already become one of the treatment options for missing teeth. In addition, under the appropriate maintenance therapy, its longevity is equal or higher compared to the other prosthetic treatments. On the other hand, patients who want to receive the implant treatment cannot avoid the insertion surgery. In addition, if there are hard or soft tissue defects at the planned site, even an additional surgery is necessary $[1,2]$. Therefore, patients who want to receive implant prosthesis often suffer from mental and physical stress in the surgical phase.

In many cases, we can reduce physical stress under the appropriate anesthesia and monitor general

\footnotetext{
* Correspondence: masahiro@dent.osaka-u.ac.jp

Department of Prosthodontics, Gerodontology and Oral Rehabilitation, Osaka University Graduate School of Dentistry, 1-8 Yamadaoka, Suita, Osaka 565-0871, Japan
}

conditions during or just before implant surgery [3]. Mental stress, such as uneasiness or fear, sometimes caused blood pressure elevation. However, this symptom gradually decreases just only by the rest at the place and does not become the problem for implant surgery in most cases. In fact, Schwarz-Arad et al. reported that there is a strong correlation between uneasiness for treatment and the experience of pain at the operation that patients received in the past [4]. They also mentioned that the degree of uneasiness became highest just before the surgery and gradually decreased at the end of the surgery. Morino et al. reported that one of the stress markers, chromogranin A level of salivary, was high be-

However, in some patient cases, many dentists experienced the uncontrolled patients even if they provided enough informed consent and appropriately managed the general condition at the surgery; as a result, they had to stop or cancel the implant surgery. One of these 
Table 1 Overview of the patients' data. All indexes were elevated just before the implant surgery

\begin{tabular}{|c|c|c|c|c|c|c|c|}
\hline No. & Sex & Age & SBP $(\mathrm{mmHg})$ & $\mathrm{DBP}(\mathrm{mmHg})$ & $\mathrm{MDP}(\mathrm{mmHg})$ & PR (bpm) & $\mathrm{RPP}(\mathrm{bpm} \times \mathrm{mmHg})$ \\
\hline \multicolumn{8}{|c|}{ First visit } \\
\hline 1 & Female & 63 & 91 & 52 & 65.0 & 68 & 6188 \\
\hline 2 & Male & 66 & 155 & 86 & 109.0 & 96 & 14,880 \\
\hline 3 & Female & 36 & 110 & 65 & 80.0 & 70 & 7700 \\
\hline 4 & Male & 54 & 139 & 92 & 107.7 & 70 & 9730 \\
\hline 5 & Male & 59 & 130 & 80 & 96.7 & 65 & 8450 \\
\hline 6 & Female & 41 & 100 & 70 & 80.0 & 72 & 7200 \\
\hline 7 & Female & 62 & 105 & 80 & 88.3 & 76 & 7980 \\
\hline 8 & Male & 72 & 130 & 90 & 103.3 & 67 & 8710 \\
\hline 9 & Female & 69 & 148 & 88 & 108.0 & 84 & 12,432 \\
\hline 10 & Female & 51 & 120 & 70 & 86.7 & 65 & 7800 \\
\hline 11 & Male & 68 & 110 & 70 & 83.3 & 73 & 8030 \\
\hline 12 & Female & 46 & 115 & 65 & 81.7 & 65 & 7475 \\
\hline 13 & Female & 53 & 109 & 76 & 87.0 & 72 & 7848 \\
\hline 14 & Female & 66 & 135 & 65 & 88.3 & 74 & 9990 \\
\hline \multirow[t]{2}{*}{15} & Female & 59 & 117 & 80 & 92.3 & 66 & 7722 \\
\hline & Mean (SD) & $57.6 \pm 10.3$ & $121.2 \pm 17.5$ & $74.9 \pm 10.9$ & $90.4 \pm 12.1$ & $72.2 \pm 8.3$ & $8809.0 \pm 2224.0$ \\
\hline \multicolumn{8}{|c|}{ Just before surgery } \\
\hline 1 & Female & 63 & 124 & 65 & 84.7 & 70 & 8680 \\
\hline 2 & Male & 66 & 175 & 98 & 123.7 & 103 & 18,025 \\
\hline 3 & Female & 36 & 128 & 81 & 96.7 & 108 & 13,824 \\
\hline 4 & Male & 54 & 141 & 92 & 108.3 & 84 & 11,844 \\
\hline 5 & Male & 59 & 143 & 99 & 113.7 & 63 & 9009 \\
\hline 6 & Female & 41 & 133 & 90 & 104.3 & 78 & 10,374 \\
\hline 7 & Female & 62 & 156 & 91 & 112.7 & 76 & 11,856 \\
\hline 8 & Male & 72 & 116 & 74 & 88.0 & 61 & 7076 \\
\hline 9 & Female & 69 & 198 & 117 & 144.0 & 86 & 17,028 \\
\hline 10 & Female & 51 & 118 & 76 & 90.0 & 77 & 9086 \\
\hline 11 & Male & 68 & 148 & 83 & 104.7 & 80 & 11,840 \\
\hline 12 & Female & 46 & 131 & 75 & 93.7 & 66 & 8646 \\
\hline 13 & Female & 53 & 132 & 82 & 98.7 & 75 & 9900 \\
\hline 14 & Female & 66 & 159 & 96 & 117.0 & 76 & 12,084 \\
\hline \multirow[t]{2}{*}{15} & Female & 59 & 145 & 90 & 108.3 & 63 & 9135 \\
\hline & Mean (SD) & $57.6 \pm 10.3$ & $143.0 \pm 21.3$ & $87.1 \pm 12.4$ & $105.7 \pm 14.9$ & $77.7 \pm 13.6$ & $11,227.1 \pm 3108.0$ \\
\hline
\end{tabular}

reasons is thought to be the influence of the patient's character. Pavek et al. concluded that mean levels of blood pressure of 85 men during a whole day are slightly affected by particular personality traits [6]. Pilqrim et al. also mentioned that acute anxiety or uneasiness can lead to a transient rise in blood pressure [7]. However, there are few reports about these relationships in dental treatment, especially in implant treatment. The aim of this study is to investigate the relationship between patient character and blood pressure in dental implant surgery.

\section{Methods}

Fifteen patients were recruited for the present study. All the patients had never received implant treatment in the past. The patients were not accepted into this study if they met any of the following exclusion criteria: (1) experience of implant treatment in the past, (2) general contraindications to implant surgery, (3) moderate or severe hypertension or cardiovascular system disease, and (4) mental disease. All the patients were informed about the purpose of this study and provided their signed informed consent. 
Table 2 Elevation rate (ER) of each index. Blood pressure just before the surgery rose around $20 \%$

\begin{tabular}{|c|c|c|c|c|c|}
\hline \multirow[b]{2}{*}{ No. } & \multicolumn{5}{|c|}{ Elevation rate } \\
\hline & SBP (\%) & DBP (\%) & MDP (\%) & PR (\%) & RPP (\%) \\
\hline 1 & 36.3 & 25.0 & 30.3 & 2.9 & 40 \\
\hline 2 & 12.9 & 14.0 & 13.5 & 7.3 & 21 \\
\hline 3 & 16.4 & 24.6 & 20.8 & 54.3 & 80 \\
\hline 4 & 1.4 & 0.0 & 0.6 & 20.0 & 22 \\
\hline 5 & 10.0 & 23.8 & 17.6 & -3.1 & 7 \\
\hline 6 & 33.0 & 28.6 & 30.4 & 8.3 & 44 \\
\hline 7 & 48.6 & 13.8 & 27.5 & 0.0 & 49 \\
\hline 8 & -10.8 & -17.8 & -14.8 & -9.0 & -19 \\
\hline 9 & 33.8 & 33.0 & 33.3 & 2.4 & 37 \\
\hline 10 & -1.7 & 8.6 & 3.8 & 18.5 & 16 \\
\hline 11 & 34.5 & 18.6 & 25.6 & 9.6 & 47 \\
\hline 12 & 13.9 & 15.4 & 14.7 & 1.5 & 16 \\
\hline 13 & 21.1 & 7.9 & 13.4 & 4.2 & 26 \\
\hline 14 & 17.8 & 47.7 & 32.5 & 2.7 & 21 \\
\hline 15 & 23.9 & 12.5 & 17.3 & -4.5 & 18 \\
\hline Mean (SD) & $19.1 \pm 15.6$ & $17.4 \pm 14.6$ & $17.8 \pm 13.0$ & $7.6 \pm 15.0$ & $28.3 \pm 22.5$ \\
\hline
\end{tabular}

To evaluate the patients' personality trait, NEO-Five Factor Inventory (NEO-FFI) was used. All the patients answered 50 questions at the first visit and scored 040 in five dimensions: neuroticism, extraversion, openness, agreeableness, and conscientiousness. The index of physical stress was evaluated by blood pressure and pulse rate. All the patients' blood pressure (systolic blood pressure (SBP), diastolic blood pressure (DBP), mean blood pressure (MBP)) and pulse rate $(\mathrm{PR})$ were measured by a biological information monitor (Moneo BP-A308, OMRON COLIN Co., Tokyo, Japan) at the first visit, entering into the operation room without local anesthesia given before and after the surgery. Elevation rates (ER) of each blood pressure and PR were calculated. Rate pressure product (RPP) was also calculated by SBP and PR.

All the patients received implant surgery under local anesthesia (2\% lignocaine with 1:80,000 epinephrine; DENTSPLY International Inc., PA, USA), and a one- or two-stage surgical approach was selected according to the initial torque values and resonance frequency analysis (RFA). Screw-type dental implants (GENESiO Plus, GC Company, Tokyo, Japan) were used in all the patients.

SBP_ER, DBP_ER, MBP_ER, PR_ER, and RPP_ER and five dimensions of NEO-FFI were used as correlated variables. For statistical analysis, Spearman's rank correlation was used and $p<0.05$ was considered statistically significant.
This study was approved by the Ethics Committee of Osaka University Graduate School of Dentistry (H24-E16-1).

\section{Results}

Ten females and five males (mean $55.5 \pm 10.6$ years) were evaluated in this study (Table 1). Tables 2 and 3 show the patients' blood pressure, pulse rate, and NEOFFI scores. Average values of blood pressure and pulse rate at the first visit were $121.2 \mathrm{mmHg}$; SBP, $74.9 \mathrm{mmHg}$; DBP, 90.4 mmHg; MBP, 81.6 bpm; PR, RPP, 9791 bpm $\times$ $\mathrm{mmHg}$ and $143.0 \mathrm{mmHg} ; \mathrm{SBP}, 87.1 \mathrm{mmHg}$; DBP, 105.7 mmHg; MBP, 69.0 bpm; PR, RPP, 9859 bpm $\times$ $\mathrm{mmHg}$ just before the surgery. A significant positive correlation was found between DBP_ER/MBP_ER and neuroticism score $(r s=0.584,0.526, p<0.05)$. There was no significant correlation, but the same tendency was found with extraversion score ( $\mathrm{rs}=-0.478,-0.499, p=0.072$, 0.058) in DBP_ER and MBP_ER. On the other hand, there were no significant correlation between SBP_ER, PR_ER, RPP_ER, and neuroticism and extraversion scores. In addition, other personality traits have no correlation with blood pressure, pulse rate, and RPP (Table 4).

\section{Discussion}

The blood pressure is considered to be affected by many factors, including physical and psychological stress in dental treatment. From a physical aspect, there are many reports about the relationship between blood pressure and local anesthesia or pain [8-11].

In fact, Tsuchihashi et al. reported that there was a correlation between increased blood pressure and infiltrated anesthesia amount [12].

On the other hand, there are not so many studies about the blood pressure change affected by the psychological aspect.

In this study, we found that neuroticism is significantly correlated with DBP and MBP increase. Ploubidis et al. reported that a person with a high degree of neuroticism assessed with the Eysenck Personality Inventory tended to self-select situations likely to lead to adversity and distress [13]. Guasti et al. also found that there was a positive correlation between provoked stress and blood pressure change using mental arithmetic stress test [14]. In addition, Eli et al. found that a patient's anxiety was highest immediately before a surgical procedure compared to immediately post-operatively and at 4 weeks post-operative follow-up [15]. These results are similar to our findings. It is thought that increase of blood pressure sometimes causes hematoma formation and increases circulation blood volume. As a result, the burden to physical condition including cardiac function is expected. Rate pressure product (RPP), which had no 
Table 3 NEO-FFI score of the patients. This questionnaire can evaluate the patient's personal trait in five categories

\begin{tabular}{llllll}
\hline \multirow{2}{*}{ No. } & NEO-FFI score & & & & \\
\cline { 2 - 6 } & Neuroticism & Extraversion & Openness & Agreeableness & Conscientiousness \\
\hline 1 & 27 & 20 & 27 & 32 & 26 \\
3 & 14 & 27 & 35 & 24 & 27 \\
4 & 23 & 28 & 25 & 30 & 19 \\
5 & 19 & 10 & 28 & 30 & 27 \\
6 & 33 & 25 & 23 & 30 & 18 \\
7 & 22 & 27 & 32 & 30 & 28 \\
8 & 19 & 32 & 30 & 29 & 28 \\
9 & 14 & 23 & 25 & 25 & 28 \\
10 & 32 & 24 & 24 & 36 & 26 \\
11 & 24 & 29 & 34 & 29 & 33 \\
12 & 17 & 35 & 30 & 37 & 38 \\
13 & 15 & 28 & 33 & 41 & 31 \\
14 & 9 & 21 & 30 & 25 & 21 \\
15 & 20 & 15 & 34 & 30 & 32 \\
Mean (SD) & 20 & $25.6 \pm 6.3$ & $29.3 \pm 3.8$ & $30.9 \pm 4.5$ & $27.1 \pm 5.1$ \\
\hline
\end{tabular}

correlation with personal traits in this study, is also a reliable predictor of myocardial oxygen consumption, and $\mathrm{RPP}>12,000 \mathrm{bpm} \times \mathrm{mmHg}$ is associated with myocardial ischemia [16-18].

There were no severe problems during the implant surgery because the patients in this study did not have moderate or severe hypertension or cardiovascular system disease. However, we should pay enough consideration to elder people or patients who have these systemic diseases and neuroticism or extraversion character during implant surgery. Applications such as nitrous oxide or intravenous sedation may be desirable for these patients. In fact, Ichinobe et al. reported that intravenous sedation stabilized measureable changes in blood pressure and pulse rate due to fear and anxiety about dental treatment [19].

On the other hand, there was no correlation between SBP and neuroticism character. For this reason, it is thought that the range of SBP is usually wide compared to DBP. However, there are some reports about the correlation between SBP and patients' personality trait [20]. Besides, the excessive rise in SBP during the operation may adversely affect the condition of the patients. Therefore, a further study about this relationship is necessary.

Measurement of a stress marker such as cortisol or amylase in saliva is one of the useful methods of stress evaluation. Umeanula reported that patients who

Table 4 The correlation between personal traits and blood pressure. A significant positive correlation were found between DBP_ER/ MBP_ER and neuroticism score. In addition, there was the same tendency between DBP_ER/MBP_ER and extraversion score

\begin{tabular}{|c|c|c|c|c|c|c|}
\hline & & Neuroticism & Extraversion & Openness & Agreeableness & Conscientiousness \\
\hline \multirow[t]{2}{*}{ SBP_ER (\%) } & rs & 0.158 & -0.272 & -0.047 & -0.055 & 0.149 \\
\hline & $p$ & 0.575 & 0.327 & 0.869 & 0.847 & 0.596 \\
\hline \multirow[t]{2}{*}{ DBP_ER (\%) } & rs & $0.584^{* *}$ & $-0.478^{*}$ & -0.023 & -0.271 & -0.275 \\
\hline & $p$ & 0.022 & 0.072 & 0.934 & 0.328 & 0.322 \\
\hline \multirow[t]{2}{*}{ MBP_ER (\%) } & rs & $0.526^{* *}$ & $-0.499 *$ & -0.077 & -0.299 & -0.201 \\
\hline & $p$ & 0.044 & 0.058 & 0.784 & 0.279 & 0.472 \\
\hline \multirow[t]{2}{*}{ PR (\%) } & rs & 0.050 & 0.250 & 0.334 & 0.200 & -0.368 \\
\hline & $p$ & 0.859 & 0.368 & 0.224 & 0.474 & 0.177 \\
\hline \multirow[t]{2}{*}{$\mathrm{RPP}(\mathrm{bpm} \times \mathrm{mmHg})$} & rs & 0.102 & 0.059 & -0.011 & 0.029 & -0.122 \\
\hline & $p$ & 0.717 & 0.834 & 0.970 & 0.918 & 0.665 \\
\hline
\end{tabular}

${ }^{*}<0.05 ;{ }^{* *}<0.1$ 
received tooth extraction had increased cortisol concentration in saliva and concluded that evaluation of a stress marker is a simple, effective method for stress evaluation [21]. However, measuring the stress marker in saliva costs time and is expense. Alternatively, we used NEOFFI for the evaluation of patients' personality trait. NEOFFI is a simple and easy questionnaire consisting of 50 questions, and we can easily analyze the character tendency of the patients into five dimensions (neuroticism, extraversion, openness, agreeableness, and conscientiousness). Yoshimura et al. revealed the validity of NEO-FFI using a large community sample in Japan [22]. Schwartz-Arad et al. reported that there was a positive correlation between the degree of anxiety and patient's expectation to experience pain during the implant surgery and concluded that in a stressful pre-surgical situation, the ability to process relevant information may be severely impaired and should not be given to patients just before the surgery [4]. Therefore, this non-invasive and simple method for evaluation of a patient's character is very useful. Besides, it is thought that the results of NEO-FFI, especially neuroticism and extraversion tendency, serve as a stress reference in not only implant treatment but also general dental treatment.

\section{Conclusions}

In this limited study, there was a significant correlation between neuroticism character and diastolic blood pressure or mean blood pressure rising in patients who received implant surgery.

\section{Authors' contributions}

MW drafted the manuscript. SM, TM, and TS collected the data in this study. $\mathrm{KI}$ analyzed the date statistically. YM participated in this study's design and helped to draft the manuscript. All authors read and approved the final manuscript.

\section{Competing interests}

Masahiro Wada, Syunta Miwa, Tomoaki Mameno, Tohru Suganami, Kazunori Ikebe, and Yoshinobu Maeda declare that they have no competing interests.

Received: 14 May 2016 Accepted: 20 October 2016

Published online: 02 November 2016

\section{References}

1. Peleg M, Sawatari Y, Marx RN, Santoro J, Cohen J, Bejarano P, Malinin T. Use of corticocancellous allogeneic bone blocks for augmentation of alveolar bone defects. Int J Oral Maxillofac Implants. 2010;25(1):153-62.

2. Cairo F, Pagliaro U, Nieri M. Soft tissue management at implant sites. J Clin Periodontol. 2008:35(8 Suppl):163-7.

3. Coulthard P. Should GDPs be checking blood pressure? Br Dent J. 2002; 193(5):269.

4. Schwartz-Arad D, Bar-Tal Y, Eli I. Effect of stress on information processing in the dental implant surgery setting. Clin Oral Implants Res. 2007;18(1):9-12.

5. Morino M, Masaki C, Seo Y, Mukai C, Mukaibo T, Kondo Y, Shiiba S, Nakamoto T, Hosokawa R. Non-randomized controlled prospective study on perioperative levels of stress and dysautonomia during dental implant surgery. J Prosthodont Res. 2014;58(3):177-83.

6. Pavek K, Taube A. Personality characteristics influencing determinacy of day and night blood pressure and heart rate. Blood Press. 2009;18(1-2):30-5.

7. Pilgrim JA. Psychological aspects of high and low blood pressure. Psychol Med. 1994;24(1):9-14.
8. Abraham-Inpijn L, Borgmeijer-Hoelen A, Gortzak RA. Changes in blood pressure, heart rate, and electrocardiogram during dental treatment with use of local anesthesia. J Am Dent Assoc. 1988;116(4):531-6.

9. Gortzak RA, Oosting J, Abraham-Inpijn L. Blood pressure response to routine restorative dental treatment with and without local anesthesia. Continuous noninvasive blood pressure registration with a finger manometer. Oral Surg Oral Med Oral Pathol. 1992;73(6):677-81.

10. Hasse AL, Heng MK, Garrett NR. Blood pressure and electrocardiographic response to dental treatment with use of local anesthesia. J Am Dent Assoc. 1986;113(4):639-42.

11. Beck FM, Weaver 2nd JM. Blood pressure and heart rate responses to anticipated high-stress dental treatment. J Dent Res. 1981;60(1):26-9.

12. Tsuchihashi T, Takata Y, Kurokawa H, Miura K, Maruoka Y, Kajiyama M, Fujishima M. Blood pressure response during dental surgery. Hypertens Res. 1996:19(3):189-94.

13. Ploubidis GB, Frangou S. Neuroticism and psychological distress: to what extent is their association due to person-environment correlation? Eur Psychiatry. 2011;26(1):1-5.

14. Guasti L, Diolisi A, Gaudio G, Grimoldi P, Petrozzino R, Uslenghi S, Bertolini A, Grandi AM, Venco A. Reactivity of blood pressure to mental arithmetic stress test, stress-test recovery time, and ambulatory blood pressure in hypertensive and normotensive subjects. Blood Press Monit. 1998:3(5):275-80.

15. Eli I, Schwartz-Arad D, Baht R, Ben-Tuvim H. Effect of anxiety on the experience of pain in implant insertion. Clin Oral Implants Res. 2003;14(1):115-8.

16. Gobel FL, Norstrom LA, Nelson RR, Jorgensen CR, Wang Y. The rate-pressure product as an index of myocardial oxygen consumption during exercise in patients with angina pectoris. Circulation. 1978;57:549-56.

17. White WB. Heart rate and the rate-pressure product as determinants of cardiovascular risk in patients with hypertension. Am J Hypertens. 1999;12:50S-5.

18. Urban MK, Gordon MA, Harris SN, O'Connor T, Barash PG. Intraoperative hemodynamic changes are not good indicators of myocardial ischemia. Anesth Analg. 1993;76:942-9.

19. Ichinohe T, Kaneko Y, Nakakuki T, Aida H, Abe H. Systemic management of dental patients with cardiovascular disease. Anesth Prog. 1989;36:219-21.

20. Garcez FB, Carvalho FU, Soares AP, Goes TC, Dos Santos MR, Teixeira-Silva F. The influence of trait anxiety on the elevation of arterial pressure induced by L-NAME in rats. Neurosci Lett. 2014;583:11-5.

21. Umeanuka OT, Saheeb BD, Uguru CC, Chukwuneke FN. Evaluation of cortisol concentrations in saliva as a measure of stress in patients having routine dental extractions. Br J Oral Maxillofac Surg. 2015;53(6):557-60.

22. Yoshimura K, Ono Y, Nakamura K, Nathan JH, Suzuki K. Validation of the Japanese version of the NEO Five-Factor Inventory in a large community sample. Psychol Rep. 2001;88(2):443-9.

\section{Submit your manuscript to a SpringerOpen ${ }^{\circ}$ journal and benefit from:}

- Convenient online submission

- Rigorous peer review

- Immediate publication on acceptance

- Open access: articles freely available online

- High visibility within the field

- Retaining the copyright to your article

Submit your next manuscript at springeropen.com 